\title{
ĐÁNH GIÁ KẾT QUẢ ĐIỀU TRI Ổ ÁP XE GAN TRÊN 5 CM BẰNG SONDE DẪN LƯU
}

\section{TÓM TẮT}

Mục tiêu: Đánh giá hiệu quả điều trị ổ áp xe gan bằng phương pháp dẫn lưu bằng sonde qua da kết hợp với điều trị nội khoa. Đối tượng và phương pháp : Tổng số 36 bệnh nhân chẩn đoán abcess gan được chẩn đoán tại khoa tiêu hóa bệnh viện Bạch mai từ năm 2015-2016. Với ổ áp xe lớn hơn $5 \mathrm{~cm}$, được điều trị bằng phương pháp dẫn lưu qua sonde. Kết quả: 36 bệnh nhân gồm 23 nam và 13 nữ, tuổi từ 19 đến 86 tuổi, trung bình 53 tuổi đều được điêuu trị thành công bằng dần lưu ổ áp xe bằng sonde qua da. Triệu chứng sốt gặp ở $97 \%$ và đau tức hạ sườn phải gặp ở $89 \%$, đây là các dấu hiệu thường gặp ở bệnh nhân áp xe gan. Thời gian lưu sonde từ 2 đến 25 ngày, trung bình thời gian lưu sonde 9.5 ngày. Thời gian nằm viện của bệnh nhân được đặt sonde dẫn lưu là 17.8 ngày, trung bình từ 4 đến 39 ngày. Không có biến chứng nào nă̆ng được ghi nhận. Kết luận: Nghiên cứu cho thấy rằng dẫn lưu qua da điều trị những ổ áp xe gan lớn trên $5 \mathrm{~cm}$ là phương pháp hiệu quả và an toàn.

Tư khóa: Áp xe gan, dẫn lưu qua da

\section{SUMMARY}

\section{PERCUTANEOUS TREATMENT OF LIVER} ABSCESS WITH DIAMETER LARGER THAN 5 CM

Objective: To assess the effectiveness of a minimally invasive percutaneous drainage of liver abscesses. Subjects and methods: A total of 36 patients were treated for liver abscess in the years 2015-2016 in Bach mai hospital. The treatment involved sonographically guided percutaneous drainage of liver abscess with diameter larger than 5 $\mathrm{cm}$. Results: A total of 36 patients ( 23 males and 13 females, age range, $19-86$ years, average age, 53 years) were successfully cured with invasive percutaneous drainage. Fever (97\%) and pain and tenderness in upper abdomen $(89 \%)$ are the common symtoms in patients with liver abscesses. Duration of catheter drainage varied from $2-25$ days, average 9.5 days. The average hospital stay of the patients who underwent percutaneous pigtail sonde drainage were 17.8 days, arrange $4-39$ days. No major complications were encountered. Conclusions: Percutaneous drainage is effective and safe in the treatment of liver abscesses diameter larger than $5 \mathrm{~cm}$.

Keywords: liver abscess, percutaneous drainage

\footnotetext{
1 Trung tâm tiêu hóa gan mật bệnh viện Bạch mai ²Bênh viên đa khoa tỉnh Bắc Ninh Chịu trách nhiệm chính: Nguyễn Công Long Email: nguyenconglongbvbm@gmail.com Ngày nhận bài: 2.8.2021

Ngày phản biện khoa học: 28.9.2021

Ngày duyệt bài: 4.10.2021
}

Nguyễn Công Long1, Trần Văn Sơn²

\section{I. ĐĂT VẤN ĐỀ}

Nễu như áp xe gan do a míp vẫn còn thường gặp ở những nước có khí hậu nhiệt đới, điều kiện xã hội, vệ sinh còn thấp thì áp xe gan do vi khuẩn lại là vấn đề đang ngày càng được quan tâm ở các quốc gia phát triển[1]. Trước đây áp xe gan ở Việt nam thường do nguyên nhân do amips với tỷ lệ gặp cao[2]. Về điều trị áp xe gan, trên thế giới đã có nhiêuu nghiên cứu với nhiều phương pháp điều trị áp xe gan được đề xuất. Có 3 phương pháp chính để điêu trị áp xe gan là điều trij nội khoa đơn thuần, điều trị nội khoa kết hợp dẫn lưu mủ áp xe gan qua da, và điều trị ngoai khoa. Điều trị áp xe gan hiện nay, theo nhiều tác giả thì phương pháp điều trị nội khoa hợp lý kết hợp với can thiệp qua da là lựa chọn hàng đầu, đã đem lại thành công trong điều trị áp xe gan từ $70-100 \%$, phẫu thuât chỉ là biện pháp cứu cánh khi thật sự cần thiết[3]. Hiện nay điều trị áp xe gan bằng nội khoa kết hợp với dẫn lưu ổ áp xe dưới hướng dẫn của siểu âm đã được áp dụng vào điều trị tại Viêt Nam, tuy nhiên chưa có nhiều nghiên cứu đánh giá hiệu quả của phương pháp này trên ổ áp xe gan lớn hơn $5 \mathrm{~cm}$ vì vậy chúng tôi tiến hành nghiên cứu này.

\section{II. ĐỐI TƯƠNG VÀ PHƯƠNG PHÁP NGHIÊN CỨU}

Đối tượng: Nghiên cứu 36 bệnh nhân điều trị nội trú tại khoa tiêu hoá bệnh viện Bạch Mai được chẩn đoán xác định là áp xe gan từ tháng 01/2015 đến tháng 10/2016. Về lâm sàng: có tam chứng Fontan điển hình hoặc không điển hình. Cận lâm sàng: siêu âm và/hoặc chụp CLVT có hình ảnh ổ áp xe lớn hơn $5 \mathrm{~cm}$. Tiêu chuẩn loại trừ các bệnh nhân không đồng ý tham gia nghiên cứu.

Phương pháp: Bệnh nhân chẩn đoán áp xe gan được đặt ống thông dẫn lưu ổ áp xe gan dưới hướng dẫn của siêu âm với ổ áp xe kích thước $>5 \mathrm{~cm}$.

\section{* Chống chi đinh:}

- Bệnh nhân có rối loạn đông máu: tỷ lệ prothrombin $<50 \%$, tiểu cầu $<50 \mathrm{G} / \mathrm{l}$.

- Áp xe gan có biến chứng: võ̃, thủng.

- Bệnh nhân có cổ trướng.

\section{* Phương tiênn}

- Máy siêu âm đầu dò quét thẳng hoặc quét quạt.

- Bộ sonde dẫn lưu Pigtail 8 F.

- Dâyy dẫn đường (Guide - wire). 
- Găng, bông, gạc vô khuẩn.

- Các dụng cụ vô khuẩn khác: bơm và kim tiêm, chỉ khâu chân dẫn lưu, khay men, khay quả đậu, khăn trải có lỗ, các lọ đựng bệnh phẩm làm xét nghiệm, lam kính.

Xử lý số liệu: Sau khi thu thập đầy đủ các số liệu, quá trình xử lý được làm trên máy tính với phần mềm xử lý số liệu SPSS 16.0, tính hệ số tương quan $r$, giá trị $P<0,05$ được xác định là mức khác biệt có ý nghĩa thống kê.

\section{KẾT QUẢ NGHIÊN CỨU}

Bảng 1. Đặc điểm cận lâm sàng nhóm bệnh nhân nghiên cứu

\begin{tabular}{|c|c|c|}
\hline Triệu chứng & Số bệnh nhân (n) & Tỷ lệ (\%) \\
\hline Sốt & 35 & 97 \\
\hline Sút cân & 34 & 94 \\
\hline Đau HSP & 32 & 89 \\
\hline Dịch màng phối & 21 & 58 \\
\hline Gan to & 18 & 50 \\
\hline
\end{tabular}

\begin{tabular}{|c|c|c|}
\hline Vàng da & 8 & 22 \\
\hline Cố trướng & 5 & 14 \\
\hline Lách to & 3 & 8 \\
\hline Tống bệnh nhân & \multicolumn{2}{|c|}{36} \\
\hline
\end{tabular}

Triệu chứng lâm sàng hay gặp nhất là sốt chiếm $97 \%$, tiếp theo là sút cân gặp $94 \%$ và đau hạ sườn phải chiếm $89 \%$.

Bảng 2. Bệnh lý kèm theo khi chẩn đoán áp xe gan

\begin{tabular}{|c|c|c|}
\hline Bệnh liên quan & $\begin{array}{c}\text { Số bệnh } \\
\text { Nhân (n) }\end{array}$ & $\begin{array}{c}\text { Tỷ lệ } \\
(\mathbf{\%})\end{array}$ \\
\hline Sỏi mật & 3 & 8,3 \\
\hline Đái tháo đ̛ường & 14 & 38,9 \\
\hline Nhiếm khuấn huyết & 3 & 8,3 \\
\hline Phấu thuật ố bụng & 2 & 5,6 \\
\hline Tống bệnh nhân & \multicolumn{2}{|c|}{36} \\
\hline
\end{tabular}

Có 3 bệnh nhân có tiền sử sỏi mật chiếm $8 \%$ và 2 bệnh nhân là có tiền sử phẫu thuật ổ bụng chiếm $6 \%$.

Bảng 3. Chỉ số cận lâm sàng nhóm bệnh nhân nghiên cứu

\begin{tabular}{|c|c|c|c|c|}
\hline Xét nghiệm & Phân loại & $\mathbf{n}$ & $(\%)$ & $\begin{array}{l}\text { Trung bình } \pm \text { SD } \\
\text { (min-max) Median }\end{array}$ \\
\hline $\begin{array}{l}\text { Số lượng bạch câu (G/l) } \\
\qquad(N=36)\end{array}$ & Cao & 30 & (83) & $15,8 \pm 6,4$ \\
\hline $\begin{array}{c}\text { Số lượng BCTT (G/l) } \\
(N=36)\end{array}$ & $\begin{array}{c}\text { Cao } \\
\text { Bình thường }\end{array}$ & $\frac{0}{28}$ & $\begin{array}{l}(78) \\
(22)\end{array}$ & $\begin{array}{c}13,0 \pm 6,2 \\
(4,3-29,9) 10,8\end{array}$ \\
\hline $\begin{array}{l}\text { Pro-Calcitonin (ng/ml) } \\
(\mathrm{N}=27)\end{array}$ & $\begin{array}{c}\text { Cao } \\
\text { Bình thường }\end{array}$ & $\frac{23}{4}$ & $\begin{array}{l}(85) \\
(15)\end{array}$ & $\begin{array}{c}8,8 \pm 20,22 \\
(0,08-105,00) 3,09\end{array}$ \\
\hline $\begin{array}{c}\text { CRP }(\mathrm{mg} / \mathrm{dl}) \\
(\mathrm{N}=23)\end{array}$ & $\begin{array}{c}\text { Cao } \\
\text { Bình thường }\end{array}$ & $\begin{array}{c}22 \\
1 \\
\end{array}$ & $\begin{array}{l}(96) \\
(04)\end{array}$ & $\begin{array}{c}53,65 \pm 97,18 \\
(0,43-343,77) 14,91 \\
\end{array}$ \\
\hline
\end{tabular}

Số lượng bạch cầu trung bình: $15,8 \pm 6,4(\mathrm{G} / \mathrm{l})$, số lượng bạch cầu lớn nhất là 33,1 G/I. 30 bệnh nhân có số lượing bạch cầu cao chiếm $83 \%$.

Bảng 4. Đặc điểm ổ áp xe gan

\begin{tabular}{|c|c|}
\hline Số lượng ố áp xe & $\mathbf{n}(\%)$ \\
\hline 1 ố & $33(91,7)$ \\
\hline 2 ố & $1(2,8)$ \\
\hline 3 ố & $2(5,6 \%)$ \\
\hline Kích thước ố áp xe & $\mathrm{cm}$ \\
\hline Trung bình \pm SD & $8,54 \pm 2,12$ \\
\hline (min - max) & $(5,2-14,8)$ \\
\hline
\end{tabular}

Có 33 bệnh nhân chỉ có 1 ố áp xe gan duy nhất (chiếm 91,7\%). Kích thước ổ áp xe trung bình là $8,54 \pm 2,12 \mathrm{~cm}$. Kích thước nhỏ nhất của ổ áp xe là $5,20 \mathrm{~cm}$ và kích thước lớn nhất là $14,8 \mathrm{~cm}$.

Bảng 5. Kết quả cây mủ ố áp xe gan

Kết quả cấy mủ Số bệnh nhân $\mathbf{n}(\%)$

Escherichia coli Klebsiella pneumoniae $\quad 1(2,8)$ Âm tính Tổng $15(42,7)$ $20(55,5)$ $36(100)$

Kết quả cây mủ có 16 bệnh nhân $(44,45 \%)$ dương tính. Klebsiella pneumonia là 15 trường hợp chiếm $41,7 \%$ và 1 là Escherichia Coli chiếm
2,8\% tổng số bênh nhân.

Bảng 5. Kêt quả kích thước ổ áp xe gan

\begin{tabular}{|c|c|c|}
\hline \multirow{2}{*}{$\mathbf{n}=\mathbf{3 6}$} & $\begin{array}{c}\text { Trước đặt } \\
\text { sonde }\end{array}$ & $\begin{array}{c}\text { Sau rút } \\
\text { sonde }\end{array}$ \\
\cline { 2 - 3 } & Trung bình \pm SD (min - max $)$ \\
\hline $\begin{array}{c}\text { Kích thước lớn } \\
\text { nhất ố áp xe (cm) }\end{array}$ & $\begin{array}{c}8,5 \pm 2,1 \\
(5,2-14,8)\end{array}$ & $\begin{array}{c}4,8 \pm 1,7 \\
(1,8-10,0)\end{array}$ \\
\hline p & \multicolumn{2}{|c|}{0,001} \\
\hline
\end{tabular}

Bảng 6. Kêt quả quả diều trị và số ngày nằm viện

\begin{tabular}{|c|c|}
\hline $\begin{array}{l}\text { Biến số } \\
(N=36)\end{array}$ & $\begin{array}{c}\text { Trung bình } \pm \text { SD } \\
\text { (median) (min-max) }\end{array}$ \\
\hline $\begin{array}{l}\text { Số ngày hết sốt } \\
\text { (ngày) }\end{array}$ & $\begin{array}{c}5,14 \pm 7,08(2,5) \\
(0-30)\end{array}$ \\
\hline $\begin{array}{l}\text { Thời gian lưu sonde } \\
\text { (ngày) }\end{array}$ & $\begin{array}{l}9,47 \pm 6,52 \\
(2-25)\end{array}$ \\
\hline $\begin{array}{l}\text { Thời gian nằm viện } \\
\text { (ngày) }\end{array}$ & $\begin{array}{c}17,83 \pm 8,47 \\
(4-39)\end{array}$ \\
\hline $\begin{array}{l}\text { Lượng mủ dân lưu } \\
(\mathrm{ml})\end{array}$ & $\begin{array}{c}520,4 \pm 454,1 \\
(42-2400)\end{array}$ \\
\hline
\end{tabular}


Không có bệnh nhân nào có những tai biến lớn (võ ổ áp xe, chảy máu đường mật) do đặt sonde gây ra. Chỉ có 1 bệnh nhân bị tắc sonde dẫn lưu.

\section{BÀN LUẬN}

Nhóm bệnh nhân trong nghiên cứu của chúng tôi có độ tuổi trung bình là $53,1 \pm 15,7$ tuổi. Tuổi trung bình trong nhóm bệnh nhân của chúng tôi cao hơn của tác giả Malik [4]. Trong nhóm nghiên cứu của chúng tôi tỷ lệ nam giới gặp nhiều hơn nữ giới với tỷ lệ nam giới là $63,9 \%$. Tỷ lệ nam/ nữ là 1,77 . Trong số 36 bệnh nhân nghiên cứu, tất cả đều được lấy mủ gửi vi sinh cây định danh vi khuẩn bằng máy tự động. Kết quả có 20 bệnh nhân âm tính và 16 bệnh nhân dương tính với những loại vi khuẩn khác nhau. Trong nhóm bệnh nhân cấy mủ âm tính thì có 2 bệnh nhân có cả xét nghiệm Elisa a míp và Elisa sán lá gan lớn đều âm tính. Do đó, trong nghiên cứu của chúng tôi có thể xem là bao gồm 18 bệnh nhân áp xe gan vi khuẩn (16 cấy mủ dương tính và 2 cây mủ âm tính) chiếm $50 \%$ bệnh nhân, và 18 bệnh nhân là áp xe gan không được xác định rõ chiếm $50 \%$. Kích thước ổ áp xe trung bình trong nghiên cứu của chúng tôi là $8,54 \pm 2,12 \mathrm{~cm}$, tất cả 36 bệnh nhân đều có kích thước ố áp xe lớn hơn $5 \mathrm{~cm}$ với kích thước nhỏ nhất của ổ áp xe là $5,2 \mathrm{~cm}$ và kích thước lớn nhất là $14,8 \mathrm{~cm}$, trong đó 27 bệnh nhân có đường kính ổ áp xe trong khoảng từ $5-10 \mathrm{~cm}$ chiếm 75\% số bệnh nhân, 9 bệnh nhân có ổ áp xe kích thước trền $10 \mathrm{~cm}$ phù hợp để dẫn lưu qua sonde pigtail so với các tác giả nước ngoài [1, 5]. Số thủ thuật được thực hiện trong nghiên cứu là 37 lượt, với tỷ lệ thành công của thủ thuật là $100 \%$. Tỷ lệ này cao như vậy là do thủ thuật được thực hiện dưới sự hướng dẫn của siêu âm và bác sỹ làm thủ thuật có trình độ cao.
35 bệnh nhân còn lại mỗi bệnh nhân được đặt 1 sonde Pigtail dẫn lưu với 1 lần thực hiện, còn lại 1 bênh nhân được đăt sonde 2 lần. Bệnh nhân này chỉ có 1 ổ áp xe, lúc đầu tiên được đặt dẫn lưu bằng sonde Pigtail cõ $8 \mathrm{~F}$ nhưng do mủ áp xe đặc, kích thước lớn, ổ áp xe có nhiều khí nên phải thay bằng sonde dẫn lưu có kích thước lớn hơn (12 F), một số bệnh nhân phải đặt nhiêu lần giống như một số tác giả khác trên thế giới $[3,4,6]$.

Sau khi điều trị thì tất cả các chỉ số viêm đều có sự cải thiện hơn so với trước khi điều trị, tất cả bệnh nhân đều hết sốt, nó khẳng định hiệu quả của phương pháp điều trị này.

\section{KẾT LUÂN}

Qua nghiên cứu 36 bệnh nhân áp xe gan lớn trên 5 được điều trị bằng nọi khoa kết hợp với đặt sonde Pigtail chúng tôi nhận thấy rằng đây là phương pháp là hiệu quả và an toàn.

\section{TÀI LIÊU THAM KHẢO}

1. Ruiz-Hernández, J.J., et al., Pyogenic liver abscesses: mortality-related factors. Eur J Gastroenterol Hepatol, 2007. 19(10): p. 853-8.

2. Blessmann, J., et al., Epidemiology of amebiasis in a region of high incidence of amebic liver abscess in central Vietnam. Am J Trop Med Hyg, 2002. 66(5): p. 578-83.

3. Cai, Y.L., et al., Percutaneous needle aspiration versus catheter drainage in the management of liver abscess: a systematic review and metaanalysis. HPB (Oxford), 2015. 17(3): p. 195-201.

4. Malik, A.A., et al., Pyogenic liver abscess: Changing patterns in approach. World J Gastrointest Surg, 2010. 2(12): p. 395-401.

5. Mischinger, H.J., et al., Pyogenic liver abscess: studies of therapy and analysis of risk factors. World J Surg, 1994. 18(6): p. 852-7; discussion 858.

6. Qian, $Y_{.,}$et al., A retrospective study of pyogenic liver abscess focusing on Klebsiella pneumoniae as a primary pathogen in China from 1994 to 2015. Sci Rep, 2016. 6: p. 38587.

\section{NGHIÊN CỨU NỒNG Độ IL-6 HUYẾT TƯƠNG, CHỈ SỐ HOMA2-IR TRÊN BÊ̂NH NHÂN ĐÁI THÁO ĐƯỜNG TYP2}

\section{TÓM TẮT}

\author{
*Bênh viên Bach Mai \\ Chịu trách nhiệm chính: Nguyễn Thị Duyên \\ Email: duyen90108@gmail.com \\ Ngày nhận bài: 26.7.2021 \\ Ngày phản biên khoa hoc: 20.9.2021 \\ Ngày duyệt bài: 29.9.2021
}

\section{Nguyễn Thị Duyên*, Bùi Tuấn Anh*}

Đái tháo đường typ2 (ĐTĐ typ2) hiện đang là một vấn đề lớn của sức khỏe toàn câu. Bềnh có cơ chế bệnh sinh phức tạp trong đó có tình trạng đề kháng insulin. Chỉ số HOMA2-IR là một chỉ số đánh giá tình trạng kháng insulin một cách khách quan, ít can thiệp. Interleukin-6 là môt cytokine có mối liên quan đển tình trạng béo phì, kháng Insulin ở bệnh nhân ĐTĐ typ2. Trong nghiên cứu này chúng tôi tính toán chỉ số HOMA2-IR và định lượng IL-6 ở bệnh nhân ĐTĐ type2 